This is an open access article under the CC-BY-SA license (https://creativecommons.org/licenses/by-sa/4.0/) ISSN 2355-6102 (print), ISSN 2502-0404 (online)

\title{
MANAJEMEN SUNGAI KLAWING UNTUK KELESTARIAN IKAN SPESIES ASLI
}

\author{
Ayesha Hafizh Gunara ${ }^{1)}$, Siti Rukayah ${ }^{2)}$ \\ ${ }^{1)}$ Manajemen Sumberdaya Perairan, Fakultas Perikanan dan Ilmu Kelautan, Universitas Jenderal Soedirman \\ 2) Biologi, Universitas Jenderal Soedirman \\ 1) E-mail : ayeshahafizhgunara@gmail.com \\ ${ }^{2)}$ E-mail : rukayah.siti@ymail.com
}

Naskah diterima 6 Agustus 2019, dan disetujui 29 Agustus 2019

\begin{abstract}
This study aims to determine the water quality in the Klawing River, riparian vegetation, native and introduced fish, utilization, the presence of pollutant reources, fishing practices, and regional regulations related to the Klawing River. Research methods by surveying and searching libraries. The results showed that the condition of water quality in the Klawing River upstream was in good condition, while the middle and downstream parts had decreased. Riparian vegetation in the upper reaches is still dominated by trees compared to the middle and downstream. Along the Klawing River there are still many locations that have the potential for erosion. There are 23 species of fish found along the Klawing River. Among these species, there are 16 species of native fish species and 7 species of introduced fish species. The source of pollution in the Klawing River comes from liquid waste and solid waste. Fishing is done by using fishing gear such as fishing rods, nets, stone cages, but there are still those who use drugs and stroom. Existing regulations on the Klawing River only refer to government regulations governing the river because it does not yet have a special PERDA.
\end{abstract}

Keywords: Klawing River, River Management, Fish Species, Water Quality

\section{PENDAHULUAN}

Sungai merupakan tempat, wadah, serta jaringan pengairan air mulai dari mata air sampai muara. Keberadaan sungai dengan sifatnya yang mengalir dari hulu ke hilir memiliki potensi opportunity value dan externality effect antara hulu-hilir atau di sepanjang aliran sungai (Pangesti, 2000). Salah satu sungai yang ada di Indonesia yaitu Sungai Klawing.

Sungai Klawing terletak di daerah Purbalingga Jawa Tengah (Widagdo et al., 2012). Sungai Klawing merupakan salah satu anakan Sungai Serayu yang memiliki luas kurang lebih 1.725,1306 km2. Sungai Klawing melewati beberapa daerah di Purbalingga seperti Karangreja pada bagian hulu, Bobotsari pada bagian tengah, dan Kemangkon pada bagian hilir. Sungai Klawing merupakan habitat bagi ikan tawar yang terdiri dari 213 spesies yang telah ditemukan. Beberapa diantaranya ialah ikan spesies asli. Ikan asli merupakan ikan yang terdapat pada suatu wilayah atau ekosistem secara alami tanpa campur tangan manusia (Groombridge, 1992). Ikan yang ditemukan di Sungai Klawing, diantaranya Puntius orphoides, Hampala macrolepidota, Barbonymus, dll. Selain sebagai tempat tinggal biota, Sungai Klawing juga dimanfaatkan oleh masyarakat. Penggunaan lahan berbeda di sepanjang Sungai Klawing, dengan hutan tanaman dan sistem pertanian intensif di daerah hulu, pemukiman di daerah tengah sungai, dan pertanian di daerah hilir. Sungai Klawing banyak dimanfaatkan oleh masyarakat sekitar untuk kegiatan perikanan, penambangan pasir dan tambang batu (Suryaningsih et al., 2018).

Pemanfaatan alur sungai dilakukan oleh masyarakat setempat untuk berbagai keperluan, dari pertanian sampai ke permukiman (Darmanto dan Sudarmadji, 2013). Pembangunan permukiman yang mengikuti pola aliran sungai bisa disebabkan ketika lahan untuk pemukiman semakin sulit ditemukan hal ini dikarenakan kondisi fisik di 
daerah tersebut tidak layak untuk dijadikan tempat pemukiman yang akan mengakibatkan rawan bencana longsor yang diakibatkan banjir (Hakki et al.,2015). Selain itu, Sungai Klawing digunakan untuk memenuhi kebutuhan sehari-hari seperti MCK (mandi, cuci, kakus), tambak, dan sebagai objek wisata (Simanjuntak et al., 2017).

Pemanfaatan sungai yang dilakukan oleh masyarakat dengan berbagai aktivitas akan menimbulkan permasalahan yang berkaitan dengan kelestarian lingkungan, kebersihan, dan penurunan kualitas air. Penurunan kualitas lingkungan di sekitar sungai tersebut disebabkan oleh berbagai hal, antara lain pembuangan limbah industri maupun limbah rumah tangga, sampah dan kebiasaan masyarakat. Perilaku semacam ini tidak mendukung terhadap lingkungan bersih yang akan menurunkan kualitas lingkungan hidup (Nasikin Muhammad, 2007). Penurunan kualitas lingkungan akan berdampak pada populasi ikan yang ada di Sungai Klawing.

Masyarakat yang berada di sekitar Sungai Klawing juga banyak yang menangkap ikan dengan cara memancing, menggunakan jala, jarring dan seser. Namun, banyak juga ditemukan penangkapan ikan dengan cara yang berbahaya dan dapat menyebabkan kerusakan lingkungan seperti listrik, racun, dan bom. Kegiatan penangkapan di Sungai Klawing yang berakibat menurunnya populasi sehingga kelimpahan dan keanekaragaman jenis ikan di Sungai Klawing akan terus mengalami penurunan, sehingga perlu adanya peraturan yang mengatur kegiatan di Sungai Klawing. Upaya pemerintah lebih bersifat preventif sebagaimana tercantum dalam Peraturan Pemerintah Nomor 35 Tahun 1991 Tentang Sungai pada Pasal 27 Bab XII. Undang-undang tersebut dalam pelaksanaannya masih diabaikan oleh masyarakat (Latif, 1995 : 48).

Penelitian terdahulu oleh Suryaningsih et al. (2018) mengenai keragaman dan distribusi longitudinal ikan di Sungai Klawing menyebutkan bahwa terdapat delapan spesies dari tujuh famili ikan yaitu Cyprinidae, Bagridae, Mastacembelidae, Anabantidae, Cichlidae, Channidae, Eleotrididae,
Beleontinidae, Osphronemidae, Poecilidae, dan Siluridae yang dilakukan di sembilan stasiun dan belum banyak mengkaji mengenai aspek manajemen Sungai Klawing. Informasi mengenai manajemen Sungai Klawing masih relatif sedikit, sehingga penelitian tentang manajemen Sungai Klawing untuk kelestarian spesies endemik perlu dilakukan.

Penelitian ini bertujuan untuk mengetahui kualitas air di Sungai Klawing, riparian vegetasi, ikan asli dan konduksi, pemanfaatan, keberadaan pollutan reources, praktik penangkapan ikan, serta peraturan daerah terkait Sungai Klawing. Penelitian ini diharapkan bermanfaat memberikan informasi mengenai manajemen Sungai Klawing untuk kelestarian spesies asli. Informasi terebut diharapkan dapat digunakan untuk melakukan pengendalian dan pengelolaan terhadap Sungai Klawing.

\section{METODE}

Metode yang dilakukan dengan cara survey yaitu meliputi pengambilan sampel di titik sampling berupa kualitas air, pengamatan meliputi kondisi riparian vegetasi dan keberadaan polutan, pemberian kuisioner meliputi ikan asli dan ikan introduksi, pemanfaatan sungai, dan praktik penangkapan yang ada di Sungai Klawing, serta penelusuran pustaka meliputi peraturan daerah tentang hukum perundangan yang ada di Sungai Klawing.

Pengumpulan data penelitian dilakukan dengan cara-cara sebagai berikut:

1. Jelajah (cruising)

Jelajah (cruising) dilaksanakan dengan melakukan pengamatan langsung dari hulu sampai ke hilir Sungai Klawing dengan mencatat kordinat lokasi terhadap proses pelaksanaan kerja dan hasil kerja untuk menilai tingkat akurasi data dan informasi yang disampaikan, dapat dilihat pada Gambar 1. 


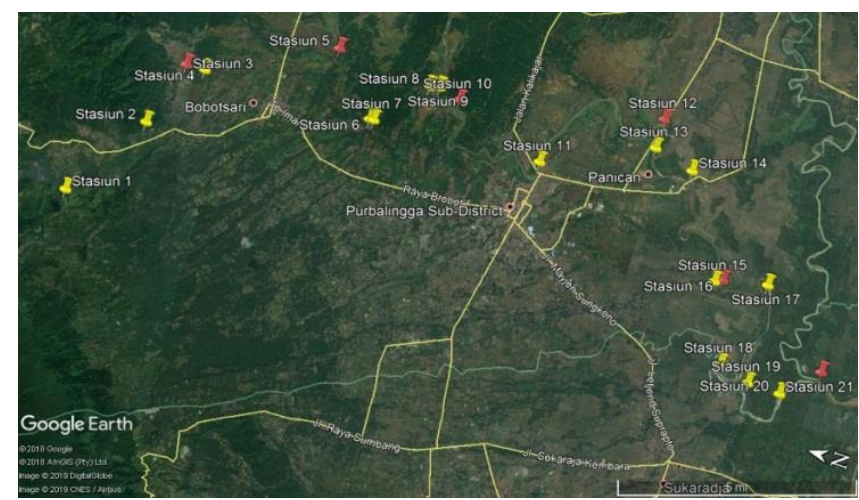

Gambar 1. Peta Tracking Sungai Klawing

\section{Wawancara}

Peneliti dan responden berhadapan langsung (face to face) untuk mendapatkan informasi secara lisan dengan tujuan mendapatkan data yang dapat menjelaskan permasalahan penelitian. Sesuai dengan jenisnya, peneliti memakai jenis wawancara tidak berstruktur adalah wawancara dengan mengajukan beberapa pertanyaan secara lebih luas dan leluasa berdasarkan susunan pertanyaan yang telah dipersiapkan sebelumnya, biasanya pertanyaan muncul secara spontan sesuai dengan perkembangan situasi dan kondisi ketika melakukan wawancara.

\section{Studi Literatur}

Studi Literatur dilakukan dengan kajian-kajian teori yang diambil dari buku/literatur, yang berkaitan dengan penelitian ini yaitu untuk mengetahui ikan asli dan ikan introduksi apa saja yang terdapat di Sungai Klawing serta hukum perundangan yang ada.

\section{Pengukuran Kualitas Air}

Parameter yang diukur meliputi oksigen terlarut, $\mathrm{pH}$, suhu, kedalaman, kecepatan arus, dan kecerahan. Pengambilan data dilaksanakan selama 1 bulan (Desember 2018), dengan melakukan pengamatan langsung dari hulu sampai ke hilir Sungai Klawing. Selanjutnya, data dianalisa dengan menggunakan analisis deskriptif dengan argumentasi dan logika ilmiah, kemudian disajikan dalam bentuk tabel serta grafik.

\section{HASIL DAN PEMBAHASAN}

1. Kualitas Air

Pengambilan dan pengukuran sampel dilakukan dengan menempatkan 6 lokasi stasiun penelitian, yaitu stasiun 1 (Palumbungan), Stasiun 2 (Karangmalang), Stasiun 3 (Bendungan Slinga), Stasiun 4 (Jembatan Toyareja), Stasiun 5 (Jembatan Wirasaba), Stasiun 6 (Congot), dengan parameter yang diukur meliputi $\mathrm{pH}, \mathrm{DO}$, suhu, kecepatan arus, kecerahan, dan kedalaman.. Berdasarkan penelitian diperoleh data sebagai berikut:

Tabel 1. Kualitas Air Sungai Klawing

\begin{tabular}{lccccccc}
\hline Parameter & St.1 & St.2 & St.3 & $\begin{array}{c}\text { St. } \\
4\end{array}$ & $\begin{array}{c}\text { St.5 } \\
\text { SH }\end{array}$ & $\begin{array}{c}\text { St. } \\
6\end{array}$ & NAB \\
\hline $\mathrm{pO}(\mathrm{mg} / \mathrm{L})$ & 5,2 & 4,8 & 2,7 & 2,82 & 3,36 & 3,78 & 24 \\
& & & & & & & \\
\hline Suhu $\left({ }^{\circ} \mathrm{C}\right)$ & 25 & 27 & 28 & 28 & 28 & 29 & $\begin{array}{c}26- \\
\end{array}$ \\
& & & & & & & 31 \\
\hline $\begin{array}{l}\text { Kecc. Anus } \\
(\mathrm{m} / \mathrm{dtk})\end{array}$ & 0,95 & 0,84 & 0,59 & 0,35 & 0,18 & 0,30 & $0,2-$ \\
\hline $\begin{array}{l}\text { Kecerahan } \\
(\mathrm{m})\end{array}$ & 5,1 & 2,6 & 5,33 & 3,36 & 3,13 & 3,67 & - \\
\hline $\begin{array}{l}\text { Kedalaman } \\
(\mathrm{m})\end{array}$ & 0,77 & 0,46 & 1,78 & 2,72 & 1,83 & 1,76 & - \\
\hline
\end{tabular}

Data kualitas air yang didapatkan relatif mengalami penurunan dari penelitian terdahulu seperti pada parameter kadar oksigen, namun pada parameter lainnya masih dalam kisaran nilai ambang batas. Penurunan kualitas air dapat terjadi karna beberapa faktor diantaranya adalah kegiatan dan pemanfaatan di sekitar Sungai Klawing, seperti pembuangan limbah domestik, pertanian, pertambangan dan industri adalah penyebab menurunnya kualitas air dari waktu ke waktu. Berikut adalah tabel hasil pengukuran kualitas air dari penelitian terdahulu : 
Tabel 2. Kualitas Air Penelitian Terdahulu

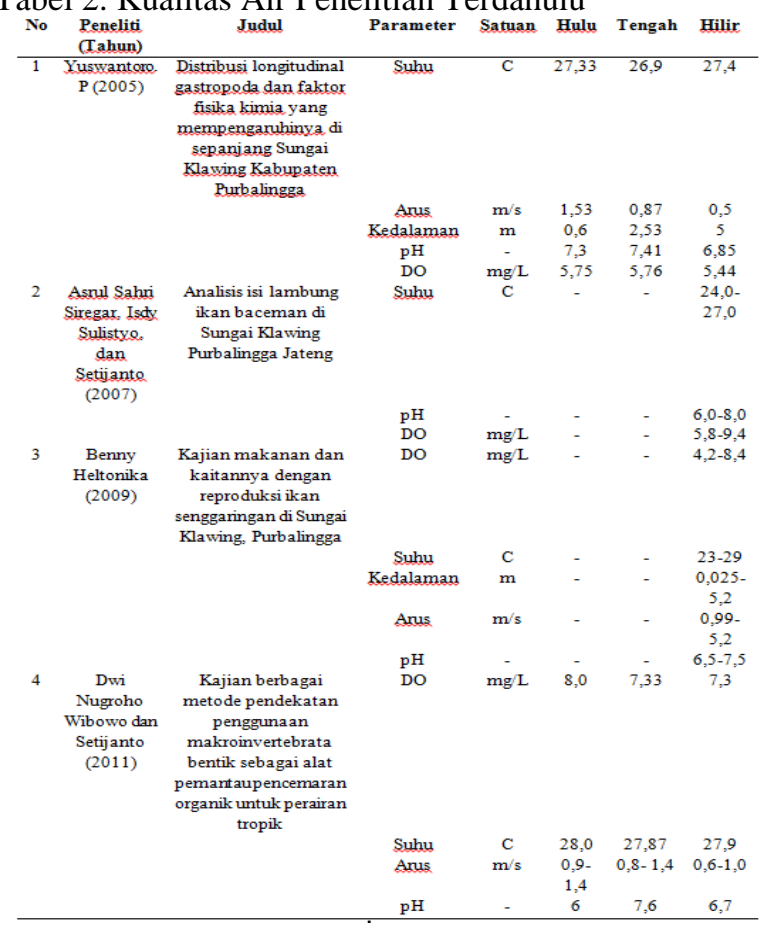

\section{Riparian Vegetasi}

Berdasarkan hasil jelajah pada 21 titik dari hulu sampai hilir Sungai Klawing, ditemukan vegetasi pembentuk ekosistem darat di Sungai Klawing yaitu pohon bambu, pohon kelapa, pohon petai cina, pohon pisang, pohon talas, pohon rambutan pohon nanas, pohon papaya, pohon singkong, pohon tebu, pohon manggis, pohon jati, pohon putat, pohon kamboja, pohon laban, pohon wirah, dan pohon durian.

Pada bagian hilir diperoleh lebih sedikit ditemukan riparian vegetasi dikarenakan di daerah ini lebih didominasi oleh pemukiman penduduk, sehingga pada lokasi tersebut lebih berpotensi terjadinya erosi. Alih fungsi lahan merupakan salah satu permasalahan tentang penggunaan lahan di sekitar Sungai Klawing. Menurut Peraturan Pemerintah No. 38 tahun 2011 pasal 1 tentang sungai, sempadan sungai adalah garis maya di kiri dan kanan paling sungai yang ditetapkan sebagai batas perlindungan sungai. Pemanfaatan lahan di sempadan sungai mengikis kawasan yang semestinya untuk resapan air sungai. Sedikitnya vegetasi menyebabkan tanah tidak dapat meresap air yang masuk sehingga akan menyebabkan erosi dan banjir ketika hujan deras.

\section{Spesies Ikan}

Berdasarkan hasil wawancara dengan Ibu Hari Setyati selaku KASI Pengembangan nelayan kecil dan perizinan dan Bapak Ragil yang merupakan pegawai Dinas Ketahanan Pangan dan Perikanan Kabupaten Purbalingga, dan wawancara yang dilakukan kepada nelayan serta masyarakat Sekitar Sungai Klawing dari hulu sampai hilir sungai, diperoleh hasil sebanyak 23 spesies ikan yang hidup di Sungai Klawing, dimana 16 spesies merupakan ikan asli dan 7 spesies merupakan ikan introduksi. Spesies yang ditemukan dalam peelitian ini disajikan seperti pada tabel 3 berikut ini.

Tabel 3. Spesies Ikan Yang Ditemukan di Sungai Kwaling

\begin{tabular}{|c|c|c|c|c|c|c|c|}
\hline \multirow{2}{*}{ No } & \multicolumn{2}{|c|}{ Ikan yang ditemukan } & \multicolumn{3}{|c|}{ Bagian Sungai } & \multicolumn{2}{|c|}{ Spesies } \\
\hline & Nama Spesies & Nama Lokal & Hulu & Tengah & Hilir & Asli & Introduksi \\
\hline 1 & Rasbora lateristriata & Lunjar & $\checkmark$ & $\checkmark$ & $\checkmark$ & $\checkmark$ & \\
\hline 2 & Rasbora argyrotaenia & Wader & $\checkmark$ & $\checkmark$ & $\checkmark$ & $\checkmark$ & \\
\hline 3 & Puntius orphoides & Brek & $\checkmark$ & $\checkmark$ & $\checkmark$ & $\checkmark$ & \\
\hline 4 & Puntius javanicus & Tawes & $\checkmark$ & $\checkmark$ & $\checkmark$ & $\checkmark$ & \\
\hline 5 & Nemacheilus fasciatus & Uceng & $\checkmark$ & $\checkmark$ & & $\checkmark$ & \\
\hline 6 & Clarias batrachus & Lele lokal & $\checkmark$ & $\checkmark$ & $\checkmark$ & $\checkmark$ & \\
\hline 7 & Orcochromis mossambicus & Mujair & $\checkmark$ & $\checkmark$ & $\checkmark$ & & $\checkmark$ \\
\hline 8 & Osteochilus hasselti & Nilem & $\checkmark$ & $\checkmark$ & & $\checkmark$ & \\
\hline 9 & Cuanna Striata & Gabus & $\checkmark$ & $\checkmark$ & & $\checkmark$ & \\
\hline 10 & Tor Tombroides & Tambra & $\checkmark$ & $\checkmark$ & & $\checkmark$ & \\
\hline 11 & Oreochromis niloticus & Nila & $\checkmark$ & $\checkmark$ & $\checkmark$ & & $\checkmark$ \\
\hline 12 & Aplocheilus panchax & Kepala timah & $\checkmark$ & $\checkmark$ & $\checkmark$ & $\checkmark$ & \\
\hline 13 & Hampala macrolepidota & Palung & $\checkmark$ & $\checkmark$ & $\checkmark$ & $\checkmark$ & \\
\hline 14 & Macrognathus mavulates & Sili & $\checkmark$ & $\checkmark$ & $\checkmark$ & $\checkmark$ & \\
\hline 15 & Osprihonemus gouramy & Gurame & & $\checkmark$ & $\checkmark$ & & $\checkmark$ \\
\hline 16 & Colossoma Macropomum & Bawal & & $\checkmark$ & $\checkmark$ & & $\checkmark$ \\
\hline 17 & Mystus micracanthus & Keting & & $\checkmark$ & $\checkmark$ & $\checkmark$ & \\
\hline 18 & Glyptothomx platypogon & Kehkel & & $\checkmark$ & $\checkmark$ & $\checkmark$ & \\
\hline 19 & Mystus nemurus & Baceman & & $\checkmark$ & $\checkmark$ & $\checkmark$ & \\
\hline 20 & Hypostomus plecostomus & Sapu-Sapu & & $\checkmark$ & $\checkmark$ & & $\checkmark$ \\
\hline 21 & Pangasius sp & Patin & & $\checkmark$ & $\checkmark$ & & $\checkmark$ \\
\hline 22 & Cyprinus carpio & Mas & & $\checkmark$ & $\checkmark$ & & $\checkmark$ \\
\hline 23 & Anguilla marmorata & Pelus & & $\checkmark$ & $\checkmark$ & $\checkmark$ & \\
\hline & Tumlah Spesies Ikan & 23 & 14 & 23 & 19 & 16 & 7 \\
\hline
\end{tabular}

\section{Pemanfaatan}

Wardana (2006) menjelaskan bahwa baik buruknya suatu perairan bisa dipengaruhi kegiatan disekitarnya. Selain itu, pemanfaatan sumberdaya perairan juga turut mempengaruhi eksistensi perairan baik secara struktural maupun fungsional. Berikut beberapa kegiatan yang terdapat di sekitar Sungai Klawing. Kegiatan yang dilakukan dan pemanfaatan di sekitar sungai Kwaling ini dapar dilihat seperti pada Tabel 4 berikut 
Tabel 4. Kegiatan dan Pemanfaatan di Sekitar Sungai Kwaling

\begin{tabular}{|c|c|c|}
\hline $\begin{array}{l}\text { Titik } \\
\text { Sampel }\end{array}$ & $\begin{array}{l}\text { Lokasi (Desa, } \\
\text { Kecamatan) }\end{array}$ & Kegiatan \\
\hline \multirow[t]{7}{*}{ Hulu } & $\begin{array}{l}1 \text { Tlahab Lor, Curug } \\
\text { Silintang }\end{array}$ & Wisata, pertanian, perkebunan \\
\hline & $\begin{array}{l}2 \text { Tlahab Kidul, Curug } \\
\text { Sumba }\end{array}$ & Wisata, pertanian, perkebunan \\
\hline & $\begin{array}{l}3 \text { Palumbungan Wetan, } \\
\text { Bobotsari }\end{array}$ & Pertanian, perkebunan, pertambangan, peternakan,budidaya, MCK \\
\hline & $\begin{array}{l}4 \text { Karang Talun, } \\
\text { Bobotsari }\end{array}$ & Pertanian, perkebunan, pertambangan, peternakan,budidaya, MCK \\
\hline & $\begin{array}{l}5 \text { Karang Malang, } \\
\text { Bobotsari }\end{array}$ & Pertanian, perkebunan, pertambangan, peternakan,budidaya, MCK \\
\hline & 6 Onje, Mrebet & Pertanian, perkebunan, pertambangan, peternakan,budidaya, MCK \\
\hline & 7 Onje, Mrebet & Pertanian, perkebunan, pertambangan, peternakan,budidaya, MCK \\
\hline \multirow[t]{5}{*}{ Tengah } & 1 Banjaran, Bojongsari & Pertanian, perkebunan, pertambangan, peternakan, MCK, bengkel \\
\hline & 2 Slinga, Kaligondang & Pertanian, perkebunan, pertambangan, MCK \\
\hline & 3 Slinga, Kaligondang & $\begin{array}{l}\text { Pertanian, perkebunan, pertambangan, peternakan, MCK, bengkel, } \\
\text { rumah makan, wisata, pemotongan unggas, tempat pembuangan } \\
\text { akhir "Banjaran", budidaya }\end{array}$ \\
\hline & $\begin{array}{l}4 \text { Penaruban, } \\
\text { Kaligondang }\end{array}$ & $\begin{array}{l}\text { Pertanian, perkebunan, pertambangan, peternakan, MCK, bengkel, } \\
\text { rumah makan, pasar, usaha meubel, dekat pusat kota, usaha knalpot, } \\
\text { cuci mobil/motor }\end{array}$ \\
\hline & 5 Toyareja, Purbalingga & $\begin{array}{l}\text { Pertanian, perkebunan, pertambangan, peternakan, MCK, bengkel, } \\
\text { rumah makan, pabrik semen, pembuatan knalpot }\end{array}$ \\
\hline Hilir & 1 Jetis, Kemangkon & $\begin{array}{l}\text { Pertanian, perkebunan, pertambangan, peternakan, MCK, bengkel, } \\
\text { rumah makan, pabrik }\end{array}$ \\
\hline
\end{tabular}


2 Bajong, Purbalingga

Pertanian, perkebunan, pertambangan, peternakan, MCK, bengkel, rumah makan, pabrik semen, pembuatan knalpot, dekat pusat kota, pembuatan bata dan genteng

3 Dusun 3, Sumilir, Kemangkon

Pertanian, perkebunan, pertambangan, peternakan, MCK, bengkel, rumah makan

4 Pengandekan, Kemangkon

Pertanian, perkebunan, pertambangan, peternakan, MCK, bengkel, rumah makan

5 Dusun 1, Sumilir, Kemangkon

Pertanian, perkebunan, pertambangan, peternakan MCK, bengkel, rumah makan, budidaya

6 Kalicupak Kidul, Kalibagor

Pertanian, perkebunan,pertambangan, peternakan, MCK, bengkel, rumah makan, budidaya

7 Kedung benda, Kemangkon

Pertanian, perkebunan, pertambangan, peternakan, MCK, bengkel, rumah makan, wisata, upacara adat

8 Sempor Kidul, Kedung Pertanian, perkebunan, pertambangan, peternakan, MCK, Benda, Kemangkon bengkel,rumah makan

9 Wisata Congot, Kedung Benda, Pertanian, perkebunan, pertambangan, peternakan, MCK, bengkel, Kemangkon

\section{Pollutan Resource}

Berdasarkan hasil pengamatan yang dilakukan di sepanjang Sungai Klawing ditemukan berbagai sumber pencemar yang berasal dari aktivitas masyarakat setempat, baik berasal dari limbah cair maupun limbah padat. Limbah cair berasal dari limbah domestik yang dibuang ke sungai oleh pemukiman yang berada di tepian sungai. Limbah padat yang berpotensi mencemari Sungai Klawing berasal dari buangan pemukiman dalam bentuk sampah. Masyarakat menjadikan lahan kosong yang berada di sepanjang sungai sebagai tempat pembuangan sampah. Sampah yang berada di sekitar sungai ini dapat terbawa arus sungai sehingga mencemari sungai.
Pembungan sampah dapat menimbulkan dampak negatif pada lingkungan. Pencemaran perairan yang ditimbulkan oleh sampah misalnya terjadi perubahan warna dan bau pada air sungai, penyebaran bahan kimia dan mikro organisme yang terbawa air hujan dan meresapnya bahan - bahan berbahaya sehingga mencemari sungai. Berbagai organisme termasuk ikan dapat mati sehingga beberapa spesies akan lenyap dan mengakibatkan berubahnya ekosistem perairan biologis (Dinas Lingkungan Hidup, 2017). 


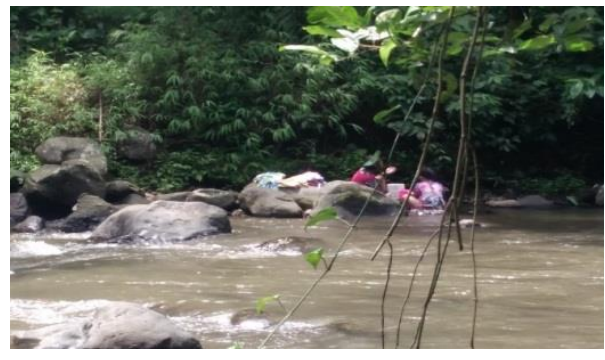

(Sumber: Dokumentasi pribadi)

Gambar 2. Contoh Sumber Pencemaran Limbah Cair Yang Berada di Daerah Onje (Kegiatan MCK)

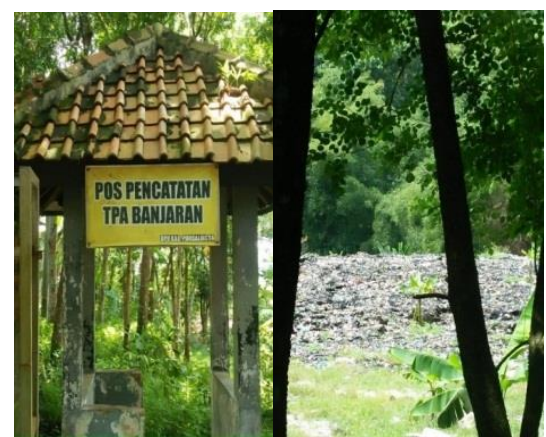

(Sumber: Dokumentasi pribadi)

Gambar 3. Contoh Sumber Pencemaran Limbah Cair Yang Berada di Daerah Slinga (TPA Banjaran)

\section{Praktik Penangkapan Ikan}

Berdasarkan hasil survey masyarakat sekitar Sungai Klawing penangkapan ikan di sungai Klawing lebih sering terjadi pada bagian hilir dan tengah daripada hulu. Pada bagian hilir selain dimanfaatkan untuk kegiatan seharihari masyarakat sekitar seperti menambang batu juga dimanfaatkan untuk menangkap ikan.

Hasil wawancara dengan beberapa narasumber, bahwa di Sungai Klawing hanya tinggal beberapa orang saja yang masih menggunakan alat tangkap yang tidak ramah lingkungan seperti racun dan stroom, hal ini dikarenakan banyaknya papan larangan akan aturan penangkapan ikan, masyarakat sekitar sungai, serta komunitas pemancing seperti Purbalingga Fun Fishing dan Mancing Mania Purbalingga yang tidak setuju dengan penggunaan alat tangkap tersebut karena dapat merusak ekosistem. Contoh gambar yang digunakan dalam peneitian seperti pada gambar 4 berikut ini.

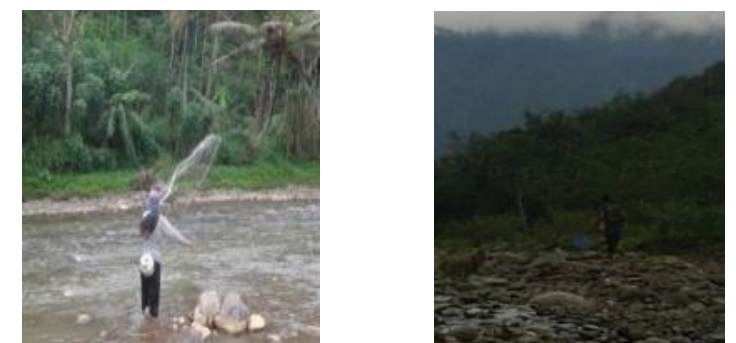

(A)

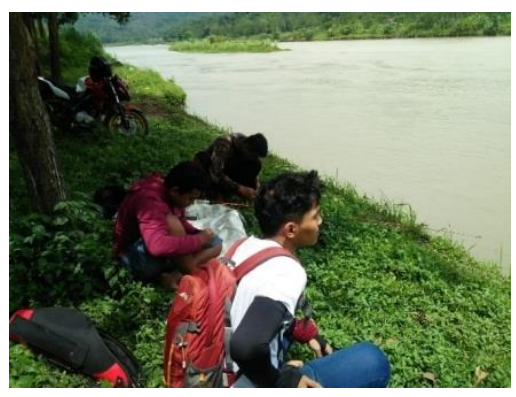

(C)

(Sumber: Dokumentasi pribadi) 1

Gambar 4. Contoh Alat Tangkap Yang Digunakan di Sungai Klawing (A. Jaring ; B. Stroom ; C. Pancing )

\section{Peraturan Daerah}

Berdasarkan wawancara dengan Dinas Ketahanan Pangan dan Perikanan Kabupaten Purbalingga yang dilakukan, belum ada hukum dan perundangan yang mengatur tentang Sungai Klawing. Namun secara umum, hukum dan perundangan mengenai sungai diatur dalam Peraturan Pemerintah No. 38 tahun 2011 tentang sungai dan Pasal 86 UU No.31 Tahun 2003 tentang perikanan.

Dalam Peraturan Daerah Gubernur Provinsi Jawa Tengah No.15 tahun 2014 tentang pengelolaan daerah aliran sungai di wilayah provinsi Jawa Tengah dalam pasal 1 nomor 8 disebutkan "Pengelolaan DAS adalah upaya manusia dalam mengatur hubungan timbal balik antar sumberdaya alam dengan manusia di dalam DAS dan segala aktivitasnya, agar terwujud kelestarian dan keserasian ekosistem serta meningkatnya kemanfaatan 
sumberdaya alam bagi manusia secara berkelanjutan".

\section{KESIMPULAN}

1. Kualitas air yang meliputi: fisika kimia sungai pada bagian hulu masih dikatakan dalam kondisi baik untuk pertumbuhan ikan, tetapi pada bagian tengah dan hilir mengalami penurunan kualitas air sehingga kurang baik bagi kehidupan organisme seperti ikan.

2. Riparian vegetasi pada bagian hulu masih di dominasi oleh pepohonan di bandingkan di bagian tengah dan hilir Sungai Klawing.

3. Di sepanjang Sungai Klawing masih banyak titik lokasi yang memiliki potensi erosi dikarenakan banyaknya penebangan pohon dan banyaknya pemukiman warga di sekitar sungai.

4. Spesies ikan yang ditemukan di sepanjang Sungai Klawing diperoleh sebanyak 23 spesies ikan, dimana terdapat 16 spesies ikan asli dan 7 spesies ikan introduksi.

5. Kegiatan yang ada di Sungai Klawing berupa usaha rumah makan, pabrik, upacara adat, usaha cuci mobil/motor, pertanian, perkebunan, peternakan, pemotongan hewan, bengkel, dan pemanfaatan Sungai Klawing yang ditemukan terdiri dari MCK, budidaya, penangkapan ikan, pertambangan batu dan pasir serta pariwisata.

6. Sumber pencemaran di Sungai Klawing berasal dari limbah cair dan limbah padat.

7. Masih ada operasi penangkapan ikan yang menggunakan cara tidak ramah lingkungan seperti penggunaan obat atau jamu dan stroom.

8. Belum ada PERDA yang mengatur khusus tentang Sungai Klawing, hanya mengacu pada peraturan pemerintah yang mengatur tentang sungai.

9. Berdasarkan hasil survey masyarakat sekitar Sungai Klawing, terdapat mitos atau legenda yang ada di bagian hulu, tengah, dan hilir Sungai Klawing.

\section{SARAN}

Berdasarkan hasil penelitian, peneliti menyarankan agar penelitian ini dapat dijadikan masukan bagi masyarakat, khususnya masyarakat sekitar Sungai Klawing, sebagai bahan evaluasi dalam pemanfaatan sungai terutama dengan adanya ikan spesies asli yang hidup di Sungai Klawing. Untuk Pemerintah Daerah Kabupaten Purbalingga agar membuat hukum perundangan khusus yang mengatur tentang Sungai Klawing, dan selalu bekerjasama dengan elemen masyarakat untuk tetap peduli akan adanya Sungai Klawing.

\section{UCAPAN TERIMAKASIH}

Puji syukur penulis panjatkan kehadirat Allah SWT atas segala limpahan rahmat, karunia dan hidayah-Nya sehingga penulis dapat menyelesaikan skripsi dengan judul

\section{"MANAJEMEN SUNGAI KLAWING} UNTUK KELESTARIAN IKAN SPESIES ASLI" dengan baik. Oleh karena itu penulis mengucapkan terimakasih sebesar-besarnya kepada:

1. Kedua orang tua yaitu Bapak Ir. Muhammad Gunara, M.Sc dan Ibu Tunas Marhaeni, serta Kakak Ns. Aisyah Kurnia Utami, S.Kep serta keluarga besar saya yang selalu memberikan dukungan, semangat, kasih sayang, dan materi kepada saya, serta membimbing penyusunan skripsi saya sehingga penyusunan penelitian ini bisa berjalan dengan lancar.

2. Bapak (Alm) Drs. H. Setijanto, M. Sc. St selaku pembimbing pertama saya yang telah memberikan izin untuk melaksanakan penelitian dan senantiasa memberi nasihat, bimbingan, arahan serta dukungannya dalam membimbing pelaksanaan penelitian hingga penyelesaian laporan.

3. Ibu Dra. Siti Rukayah, M.Si selaku pembimbing kedua yang dimana saya merasa seperti dibimbing orang tua saya sendiri karena senantiasa selalu bersabar memberikan saya arahan, dukungan serta nasihat terutama dalam hal etika dan sopan santun dalam membimbing pelaksanaan skripsi hingga penyelesaian laporan.

4. Semua pihak yang tidak dapat disebutkan satu persatu dalam membantu penyusunan dan kelancaran penelitian. 


\section{DAFTAR PUSTAKA}

Darmanto, Darmakusuma \& Sudarmadji. 2013. Pengelolaan Sungai Berbasis Masyarakat Lokal Di Daerah Lereng Selatan Gunungapi Merapi. Jurnal Manusia dan Lingkungan. 20(2): 1-11

Groombridge, B. 1992. Global Biodiversity: Status of the Earth's Living Resources. A Report compiled by WCMC in collaboration with The Natural History Museum, London, IUCN, UNEP, WWF, and WRI. ChaPman \& Hall, London.

Latif, A. 1995. Faktor-faktor yang Mempengaruhi Perilaku Penduduk dalam Pemanfaatan Sungai Code Sebagai sarana Mandi cuci dan kakus $(M C K)$, Studi Kasus di Kecamatan Jetis Kotamadya Yogyakarta. Tesis. Yogyakarta: Program Pascasarjana UGM.

Nasikin, Muhammad. 2007. Pemanfaatan Sungai Jajar Sebagai Sarana Mandi Cuci Dan Kakus (MCK),Studi Kasus Terhadap Perilaku Masyarakat di Kelurahan Singorejo Kecamatan Demak Kabupaten Demak. Tesis. Semarang: Program Pascasarjana UNNES.

Pangesti, Dyah Rahayu. 2000. Pengelolaan dan Pemanfaatan Sungai Menyongsong
Abad-21. Orasi Ilmiah APU, Depkimbangwil.

Simanjuntak, Elisa Lestari et al. 2017. Dampak Aktivitas Masyarakat Terhadap Kualitas Air Sungai Babarsari Kecamatan Kutalimbaru Kabupaten Deli Serdang. Jurnal Aquacoastmarine. 5 (4): 1-11

Suryaningsih, S., Sri, S., Sorta, B.I. S., \& Kusbiyanto. 2018. Diversity and longitudinal distribution of freshwater fish in Klawing River, Central Java, Indonesia. 19(1):85-92.

Wan Hakki et al.,2015. Dampak Pemanfaatan Bantaran Sungaiterhadap Kualitas Lingkungan Di Kelurahan Pasar Krui. Jurnal Fakultas Keguruan dan Ilmu Kependidikan. Universitas Lampung.

Widagdo, A., \& Rachmad, S. 2012. Geomorfologi Sungai Klawing Daerah Bobotsari, Kabupaten Purbalinggga, Jawa Tengah. Dinamika Rekayasa. 8(2): 1-7. 